N Engl J Med. 2009 October 29; 361(18): . doi:10.1056/NEJMra0804575.

\title{
Norovirus Gastroenteritis
}

Roger I. Glass, M.D., Ph.D., Umesh D. Parashar, M.D., M.P.H., and Mary K. Estes, Ph.D. Fogarty International Center, National Institutes of Health, Bethesda, MD (R.I.G.); the Division of Viral Diseases, National Center for Immunization and Respiratory Diseases, Centers for Disease Control and Prevention, Atlanta (R.I.G., U.D.P.); and Department of Molecular Virology and Microbiology, Baylor College of Medicine, Houston (M.K.E.)

The Norwalk agent was the first virus that was identified as causing gastroenteritis in humans, but recognition of its importance as a pathogen has been limited because of the lack of available, sensitive, and routine diagnostic methods. Recent advances in understanding the molecular biology of the noroviruses, coupled with applications of novel diagnostic techniques, have radically altered our appreciation of their impact. Noroviruses are now recognized as being the leading cause of epidemics of gastroenteritis and an important cause of sporadic gastroenteritis in both children and adults. Although norovirus gastroenteritis is generally mild and of short duration, new evidence suggests that the illness can be severe and sometimes fatal, especially among vulnerable populations - young children and the elderly - and is a common cause of hospitalization for gastroenteritis. Routine diagnostic methods are still unavailable to most clinicians, but epidemiologic studies have identified both rapid local transmission and the emergence of novel norovirus strains that spread in a global fashion, similar to the epochal patterns of influenza. Controlling outbreaks of norovirus poses major challenges. ${ }^{1}$

\section{CHARACTERISTICS AND EVOLUTION OF NOROVIRUS}

Before 1993, noroviruses were diagnosed in fecal specimens by means of electron microscopy. They were referred to in the literature by their shape (small, round, structured viruses) or by their similarity to the Norwalk agent (Norwalk-like viruses) and were named for the location in which they were found (e.g., Norwalk, OH; Hawaii; and Snow Mountain, $\mathrm{CO})$. Once sequenced, the Norwalk virus genome revealed a single positive-strand RNA approximately $7.7 \mathrm{~kb}$ in size, enclosed in a non-enveloped protein coat with distinct cupshaped depressions that placed it as a new genus — norovirus — in the family Caliciviridae (whose name is derived from calyx, which means cup in Greek). The diversity among noroviruses is great, and human strains were soon classified on the basis of their sequences into three genogroups (GI, GII, and GIV), at least 25 genotypes, and numerous subgroups, with the prototype Norwalk virus designated as GI.1 (i.e., genogroup I, genotype 1) (Fig. 1). Other strains that are identified by the location in which they were discovered have now been given genetic classifications (see Table 1 in the Supplementary Appendix, available with the full text of this article at NEJM.org). The great diversity of strains is attributed both to the accumulation of point mutations associated with error-prone RNA replication and to recombination between two related viruses. ${ }^{2,3}$ Despite this diversity, in recent years only a few strains, primarily those of genogroup II, genotype 4 (II.4), are responsible for a majority of the cases and outbreaks. Some noroviruses have been identified in animals, but none of these have yet been detected in humans.

Copyright () 2009 Massachusetts Medical Society.

Address reprint requests to Dr. Glass at Fogarty International Center, 31 Center Dr., Rm. 31 B2 C02, Bethesda, MD 20892.

No other potential conflict of interest relevant to this article was reported. 
When the capsid genes of norovirus were expressed in baculovirus, viruslike particles were produced that appeared to be indistinguishable from wild-type virus ${ }^{4}$ (Fig. 2). These viruslike particles have become key reagents for the development of diagnostic techniques, for the study of structure ${ }^{5}$ and cell attachment, and for use as candidate vaccines. Structural studies indicate that 180 molecules of the capsid protein are arranged as dimers, each divided into a shell and a protruding domain. One highly variable region of the protruding domain, P2, recognizes the histo-blood group antigens, which are regarded as receptors and host-susceptibility factors for infection. At least two distinct binding sites of histo-blood group antigens have been localized for various virus strains (Fig. 1 in the Supplementary Appendix).

An analysis of many outbreaks has identified noroviruses of the GII genogroup as the most common strains worldwide. Over the past 20 years, with the accumulation of mutations in the P2 domain, the binding patterns of histo-blood group antigens in different GII.4 noroviruses have evolved. This observation supports the notion of a genetic drift and evolution of the norovirus that has been driven by population immunity, including carbohydrate-protein interactions. ${ }^{7,8}$ The result is a pattern of epochal evolution, like that of influenza, with the emergence of norovirus variants that replace previously dominant strains and cause new worldwide epidemics. ${ }^{8,9}$

\section{LABORATORY DIAGNOSIS}

Once the sequence of norovirus was known, a molecular-based reverse-transcriptasepolymerase-chain-reaction (RT-PCR) assay became the reference method for detecting norovirus in fecal specimens, water, and food. ${ }^{10}$ Viruslike particles were used as antigen in immunoassays to detect antibody responses to infection, and antibodies to viruslike particles were developed for immunoassays to detect norovirus antigen in fecal specimens. ${ }^{10,11}$ To make accommodations for the great diversity of strains, a cocktail of primers is required for RT-PCR, and a collection of cross-reactive antibodies is required for immunoassays. Commercial immunoassays that are now available in Europe and Japan to detect antigen in stool are very specific but less sensitive, so they have been used to diagnose outbreaks in which multiple samples are tested. ${ }^{12}$ As diagnostic technologies evolve, RT-PCR is being replaced by real-time RT-PCR, which can be more sensitive and rapid and, when used with a Taqman probe, provides both confirmation and quantitation in a single assay. ${ }^{11,13,14}$

\section{EPIDEMIOLOGY AND TRANSMISSION}

The availability of more sensitive diagnostic techniques has radically changed our appreciation of the epidemiology of norovirus disease ${ }^{15}$ (Table 1). In the United States, more than $90 \%$ of the out-breaks for which the cause would previously have been unknown can now be attributed to norovirus. ${ }^{16}$ These outbreaks involve people of all ages, occur in a wide variety of settings (e.g., nursing homes, hospital wards, day-care centers, cruise ships, restaurants, and catered events), and target a number of high-risk groups, particularly young children and the elderly, travelers, soldiers, and some patients who are immunocompromised or have received organ transplants.

Humans are believed to be the only host for human norovirus. Fecal-oral spread is the primary mode of transmission, although infectious vomitus can play a role as well. Several characteristics of noroviruses facilitate their spread. First, the low infectious dose (approximately 18 to 1000 viral particles) ${ }^{17}$ allows the virus to spread through droplets, fomites, person-to-person contact, and environmental contamination, as evidenced by secondary attack rates of $30 \%$ or more among close contacts and family members. Second, viral shedding precedes the onset of illness in up to $30 \%$ of exposed persons and may continue long after the illness, increasing the potential risk of secondary spread - a 
particular concern among food handlers and family members. ${ }^{18-20}$ Third, the virus can withstand a wide range of temperatures (from freezing to $60^{\circ} \mathrm{C}$ ) and persist on environmental surfaces, in recreational and drinking water, and in a variety of food items, including raw oysters and fruits and vegetables that are irrigated with sewage and are eaten uncooked. Fourth, because of the great diversity of norovirus strains and the lack of complete cross-protection, as well as the lack of long-term immunity, repeated infections can occur throughout life. Finally, the norovirus genome easily undergoes mutation that causes antigenic shift and recombination, which, in turn, result in the evolution of new strains that are able to infect susceptible hosts.

Noroviruses are now recognized as playing a major role in sporadic gastrointestinal illnesses, as well. Early serosurveys documented a high prevalence of norovirus antibodies in children, but because the virus was rarely detected in fecal specimens, its role in causing the infection seemed questionable. With the use of RT-PCR, noroviruses are routinely detected in fecal specimens of children and adults with gastroenteritis. A recent review of studies documented norovirus in 5 to $31 \%$ of patients hospitalized for gastroenteritis and in 5 to $36 \%$ of those visiting a clinic, making it the most common cause of diarrhea in adults and the second most common cause in children (Table 2). ${ }^{21}$ The virus can be detected in water and foods that are epidemiologically linked to outbreaks.

The key role of norovirus was shown in the Study of Infectious Intestinal Disease in England. The prevalence of eight enteric pathogens was assessed by means of PCR in specimens that were obtained as part of a case-control study in a setting in which gastrointestinal infections affected approximately $20 \%$ of the population each year. ${ }^{31}$ Initially, no etiologic agents were detected in $49 \%$ of the cases, but with the use of PCR, at least one agent was found in $75 \%$ of the cases, and noroviruses were the most common, detected in $36 \%$ of cases and $18 \%$ of controls. ${ }^{15}$ Although data from developing countries are sparse, norovirus infections appear to be common in those countries as well. For example, noroviruses were detected by means of PCR in $31 \%$ and $15 \%$ of pediatric patients hospitalized with gastroenteritis in evaluations conducted in India and Peru, respectively. ${ }^{24,29}$ Collectively, these data show that noroviruses are a common cause of diarrhea leading to hospitalizations and clinic visits among adults and perhaps the second most common cause of diarrhea (after rotavirus) leading to hospitalization of children younger than 5 years of age.

A comparison of norovirus sequences collected from around the world over the course of a decade has led to the startling finding that a new pandemic strain emerges every 2 to 4 years. In recent years, the most common have been GII. 4 strains, which account for more than $80 \%$ of all norovirus outbreaks in the United States (Fig. 3). The global emergence of common strains raises public health questions about the spread of pandemic strains, which may occur through common vehicles such as foods sold internationally or through person-to-person contact when travelers carry the virus. For example, a global outbreak has been traced to fecally contaminated raspberries that were sold throughout Europe and Canada. ${ }^{32}$

\section{CLINICAL FEATURES}

In studies involving volunteers and in investigations of outbreaks, norovirus infections cause diarrhea in some of those who are exposed and vomiting in others and are asymptomatic in about one third of the volunteers. After an incubation period of 10 to 51 hours, the disease often begins with vomiting, followed by abdominal cramps, fever (in 37 to $45 \%$ of the cases), watery diarrhea, and other constitutional symptoms such as headache, chills, and myalgias. The illness normally lasts only 2 to 3 days but can last longer (i.e., 4 to 6 days) in nosocomial outbreaks and among children younger than 11 years of age. ${ }^{20,33}$ Virus can be 
shed in low titers for up to 8 weeks in previously healthy persons ${ }^{19}$ and for more than a year in patients who are immunocompromised and in those who have undergone transplantation; making a diagnosis can be critical when gastrointestinal symptoms can be an early sign of rejection or a side effect of drugs. ${ }^{34,35}$ Fatalities have been reported in association with outbreaks of gastroenteritis among the elderly in nursing home facilities, ${ }^{36,37}$ and in the United Kingdom, an estimated 80 deaths from norovirus infections occur each year among persons older than 64 years of age. ${ }^{38}$ Recent reports have suggested possible associations of norovirus infection with necrotizing enterocolitis in newborns, with benign seizures in infants, and with exacerbations of inflammatory bowel disease in pediatric patients; further study is needed to confirm these links. ${ }^{39-41}$

\section{PATHOGENESIS}

Much of our understanding of the pathogenesis of norovirus infections and of susceptibility and immunity to them comes from data on more than 1000 volunteers who have participated in challenge studies. Proximal jejunal biopsy specimens from ill volunteers showed a broadening and blunting of the intestinal villi, crypt-cell hyperplasia, cytoplasmic vacuolization, and infiltration of polymorphonuclear and mononuclear cells into the lamina propria with the mucosa itself remaining intact. No histologic changes are seen in the gastric fundus or in antrum or colonic mucosa, ${ }^{42}$ nor have they been seen in biopsy specimens obtained during the convalescent phase of the illness. The extent of involvement of the small intestine remains unknown because more distal involvement of the small intestine could not be studied, and the site of virus replication has not been identified. Enzymatic activity (alkaline phosphatase, sucrase, and trehalase) at the brush border of the small intestine is decreased, resulting in mild steatorrhea and transient carbohydrate malabsorption. ${ }^{43}$ Jejunal adenylate cyclase activity is not elevated ${ }^{42}$ and gastric secretion of hydrochloric acid, pepsin, and intrinsic factor has been associated with these histologic changes. In contrast, gastric emptying is delayed, ${ }^{44}$ and the reduced gastric motility may be responsible for the nausea and vomiting associated with this gastroenteritis. The cause of the rapid and often explosive illness remains to be fully explained on a molecular basis.

\section{HOST SUSCEPTIBILITY}

In studies involving volunteers and in investigations of outbreaks, a subgroup of people who are exposed to the virus do not become ill, a finding that suggests that there is some mechanism of natural protection. ${ }^{22}$ Although this natural protection might seem like immunity, some volunteers with high levels of antibody still become ill, whereas others who lack antibodies do not. This apparent paradox has been explained by the identification of genetically determined host-susceptibility factors related to the binding of viruslike particles to human intestinal sections and red cells. Noroviruses recognize histo-blood group antigens in a strain-specific manner. ${ }^{45}$ These complex carbohydrates - oligosaccharides linked to proteins or lipids - reside on the mucosal epithelia of the digestive tracts and are present as free oligosaccharides in saliva and milk. ${ }^{46}$ All three major families of histo-blood group antigens - the ABO, Lewis, and secretor families - are involved in binding noroviruses. ${ }^{47}$ The involvement of histoblood group antigens, and in particular secretor status controlled by the fucosyltransferase 2 (FUT2) gene, determines susceptibility to norovirus infections (Fig. 1 in the Supplementary Appendix). Persons who are nonsecretors - 20\% of Europeans are resistant to infection with the Norwalk virus (GI.1) ${ }^{48,49}$ an observation that was extended to include resistance to some genogroup II viruses. ${ }^{50,51}$ At least eight different specificity patterns of histo-blood group antigens are known, ${ }^{51}$ but the structural basis of binding specificity is fully understood only for the Norwalk virus. Comprehensive analysis of these genetically determined susceptibility associations in outbreaks will require full characterization of both the infecting virus strain and the ABO, Lewis, and secretor blood 
types of exposed and affected persons. Given the diversity of norovirus strains, persons who are resistant to one strain may be susceptible to another. The strong effect of polymorphisms in potential receptor genes on susceptibility or resistance to specific infectious agents is similar to the well-established association of polymorphisms in the chemokine CCR5 receptor with resistance to human immunodeficiency virus (HIV) infection and the discovery that the chemokine CCR5 receptor is a coreceptor for HIV infection.

\section{IMMUNITY}

The nature of immunity to norovirus is a key determinant in considering the prospect of future prevention with the use of vaccines. Norovirus disease can occur at all ages; therefore, adults remain at risk either because of weak immunity or because of the tremendous diversity of strains that do not cross-protect. In an early study of immunity to norovirus infection, some volunteers who became ill after the virus challenge had partial immunity to disease on rechallenge 6 to 14 weeks later but lost the immunity after 2 to 3 years. ${ }^{22}$ However, recent studies cast doubt on these early findings, since the dose that is required to infect $50 \%$ of volunteers is as low as 18 infectious particles, whereas the dose used in the early study was more than $10^{5}$ times higher. ${ }^{17}$ Immunity to a lower challenge dose might be substantially greater and more cross-reactive than immunity against an overwhelming challenge dose; studies to investigate this possibility are planned or ongoing.

\section{PREVENTION AND CONTROL}

The prevention of norovirus outbreaks has been extremely challenging because outbreaks that begin with a single common exposure to contaminated food or water can rapidly spread by person-to-person contact. Tracing and investigating the outbreak require segregating the very first cases from secondary cases in which the mode of transmission may be different from that of the first cases. Stopping the outbreak often requires Herculean efforts to clean the environment on cruise ships, hospital wards, or disaster sites, and even then, the epidemics have abated only when the susceptible pool has been exhausted. ${ }^{52,53}$ Knowledge of the specific sequence of the epidemic can link cases to a common exposure - such as raw oysters or contaminated foods - and occasionally identify the implicated virus in the food. Sequencing a specific variable protruding region of an outbreak strain has been useful in linking strains to a single outbreak, monitoring its evolution as the outbreak spreads, and identifying individual strains associated with prolonged transmission. ${ }^{54}$ Assays that have been used in specific outbreaks to detect noroviruses directly in contaminated food and water are now being adapted to routine screening of food or water. ${ }^{55,56}$

Current control efforts, which are only modestly effective at best, are aimed at limiting exposure to foods that have been contaminated at the source through environmental contamination (as has been the case with raspberries and oysters) or through contamination by food handlers. ${ }^{57}$ It is recommended that ill food handlers not be allowed to remain on the job and that strict personal hygiene among food handlers be enforced, but both initiatives have had limited success. A Japanese study has shown high rates of norovirus infection in asymptomatic food handlers ${ }^{58}$ and prolonged shedding of virus after infection, but the importance of low-level shedding for transmission has not been documented.

Preventing the secondary spread of the virus through person-to-person contact and from contaminated environmental surfaces is key to stopping the continuation of outbreaks such as those occurring in hospital wards and aboard cruise ships. Enforcing personal hygiene, using enteric precautions, and decontaminating environmental surfaces may help. A recent study in which mouse norovirus was used as the model has shown that hand sanitizers containing alcohol can reduce contamination. ${ }^{59} \mathrm{~A}$ recent school-based trial showed that absenteeism for norovirus infection was reduced in classrooms in which alcohol-based hand 
sanitizers were used and classroom surfaces were disinfected daily with quaternary ammonium wipes, as compared with control classrooms that followed usual hand-washing and cleaning practices. ${ }^{60}$

\section{VACCINES}

The high prevalence of norovirus infections among both children and the elderly and the limited inroads that have been made in preventing outbreaks have led some investigators to consider the potential role of vaccines in controlling the disease. The target groups for such a vaccine might include infants (as part of their routine schedule for childhood immunizations), the elderly, food handlers, military personnel, travelers, health care workers, and attendants in day-care centers. Furthermore, since noroviruses are universal infections among children and possibly the second most common cause of severe diarrhea in the developing world, vaccines could play a key role in programs that are aimed at reducing childhood mortality and controlling diarrheal disease. A recent systematic review of the literature noted that $15 \%$ of hospitalizations of children for diarrhea in India and 31\% in Peru were associated with norovirus infection, ${ }^{21}$ percentages that could contribute greatly to the estimated 1.6 million children who die each year from diarrhea.

Preclinical studies have shown that viruslike particles administered to mice as parenteral, oral, or intranasal vaccines are highly immunogenic. ${ }^{61,62}$ Among volunteers, recombinant viruslike particles expressed in transgenic plants and given orally and viruslike particles expressed in baculovirus and administered orally have both been safe and immunogenic. ${ }^{63,64}$ However, many challenges to developing norovirus vaccines remain, including an incomplete understanding of the immune correlates of protection, the lack of good long-term immunity and heterotypic protection against antigenically distinct strains, and the existence of multiple genetic and antigenic types of virus. The recent predominance of a few common strains suggests that, for the moment, vaccine candidates might require relatively few antigens. However, given the continuing and rapid evolution of the virus, an annual process of strain selection, similar to that for the influenza virus, might be needed to match the vaccine to the circulating norovirus strains. Studies testing vaccines based on viruslike particles are just beginning, and insights that are gained from these studies could well determine the ultimate feasibility of this approach.

\section{TREATMENT}

The treatment for norovirus gastroenteritis, like that for other diarrheal illnesses, is oral rehydration with fluids and electrolytes, if the patient is alert and able to drink, or with intravenous fluids, if vomiting and dehydration are severe. Antimotility and antisecretory agents can be useful in adults to decrease diarrhea in situations in which a person's performance is critical. Although no antiviral agents have yet been developed, the x-ray crystallographic structures of the viral polymerase and proteases are known, as is the binding site of histo-blood group antigens in particles, and these provide potential targets for the development of drugs. Interferons and ribavirin effectively inhibit replication of Norwalk virus in replicon-bearing cells ${ }^{65}$ and their potential therapeutic value needs to be further evaluated. Among patients receiving immunosuppressive therapy, recognition of norovirus infection could optimize case management with respect to long-term therapy for the primary disease. Administration of hyperimmune human immune globulin parenterally or orally has been suggested, but this therapy has never been studied in a clinical trial.

\section{Supplementary Material}

Refer to Web version on PubMed Central for supplementary material. 


\section{Acknowledgments}

Supported by grants from the National Institutes of Health (to Dr. Estes).

Dr. Estes reports being a consultant for and owning stock options in LigoCyte Pharmaceuticals, receiving lecture fees from Merck, and being named as an inventor on patents related to cloning of the Norwalk virus genome.

We thank Robert Atmar, M.D., and B.V.V. Prasad, Ph.D., for critical comments and help with figures and Marc Widdowson, DuPing Zheng, and Jan Vinje.

\section{REFERENCES}

1. Dolin R. Noroviruses— challenges to control. N Engl J Med. 2007; 357:1072-1073. [PubMed: 17855667]

2. Nayak MK, Balasubramanian G, Sahoo GC, et al. Detection of a novel inter-genogroup recombinant Norovirus from Kolkata, India. Virology. 2008; 377:117-123. [PubMed: 18555887]

3. Bull RA, Tanaka MM, White PA. Norovirus recombination. J Gen Virol. 2007; 88:3347-3359. [PubMed: 18024905]

4. Jiang X, Wang M, Graham DY, Estes MK. Expression, self-assembly, and anti-genicity of the Norwalk virus capsid protein. J Virol. 1992; 66:6527-6532. [PubMed: 1328679]

5. Prasad BV, Hardy ME, Dokland T, Bella J, Rossmann MG, Estes MK. X-ray crystallographic structure of the Norwalk virus capsid. Science. 1999; 286:287-290. [PubMed: 10514371]

6. Choi JM, Hutson AM, Estes MK, Prasad BV. Atomic resolution structural characterization of recognition of histo-blood group antigens by Norwalk virus. Proc Natl Acad Sci U S A. 2008; 105:9175-9180. [PubMed: 18599458]

7. Le Pendu J, Ruvoen-Clouet N, Kindberg E, Svensson L. Mendelian resistance to human norovirus infections. Semin Immunol. 2006; 18:375-386. [PubMed: 16973373]

8. Siebenga JJ, Vennema H, Renckens B, et al. Epochal evolution of GGII.4 norovirus capsid proteins from 1995 to 2006. J Virol. 2007; 81:9932-9941. [PubMed: 17609280]

9. Lindesmith LC, Donaldson EF, Lobue AD, et al. Mechanisms of GII.4 norovirus persistence in human populations. PLoS Med. 2008; 5(2):e31. [PubMed: 18271619]

10. Atmar RL, Estes MK. Diagnosis of noncultivatable gastroenteritis viruses, the human caliciviruses. Clin Microbiol Rev. 2001; 14:15-37. [PubMed: 11148001]

11. Trujillo AA, McCaustland KA, Zheng DP, et al. Use of TaqMan real-time reverse transcriptionPCR for rapid detection, quantification, and typing of norovirus. J Clin Microbiol. 2006; 44:14051412. [PubMed: 16597869]

12. Gray JJ, Kohli E, Ruggeri FM, et al. European multicenter evaluation of commercial enzyme immunoassays for detecting norovirus antigen in fecal samples. Clin Vaccine Immunol. 2007; 14:1349-1355. [PubMed: 17715333]

13. Kageyama T, Kojima S, Shinohara M, et al. Broadly reactive and highly sensitive assay for Norwalk-like viruses based on real-time quantitative reverse transcription-PCR. J Clin Microbiol. 2003; 41:1548-1557. [PubMed: 12682144]

14. Koopmans M. Progress in understanding norovirus epidemiology. Curr Opin Infect Dis. 2008; 21:544-552. [PubMed: 18725806]

15. Amar CF, East CL, Gray J, Iturriza-Gomara M, Maclure EA, McLauchlin J. Detection by PCR of eight groups of enteric pathogens in 4,627 faecal samples: re-examination of the English casecontrol Infectious Intestinal Disease Study (1993-1996). Eur J Clin Microbiol Infect Dis. 2007; 26:311-323. [PubMed: 17447091]

16. Fankhauser RL, Noel JS, Monroe SS, Ando T, Glass RI. Molecular epidemiology of "Norwalk-like viruses" in outbreaks of gastroenteritis in the United States. J Infect Dis. 1998; 178:1571-1578. [PubMed: 9815206]

17. Teunis PF, Moe CL, Liu P, et al. Norwalk virus: how infectious is it? J Med Virol. 2008; 80:14681476. [PubMed: 18551613] 
18. Graham DY, Jiang X, Tanaka T, Opekun AR, Madore HP, Estes MK. Norwalk virus infection of volunteers: new insights based on improved assays. J Infect Dis. 1994; 170:34-43. [PubMed: 8014518]

19. Atmar RL, Opekun AR, Gilger MA, et al. Norwalk virus shedding after experimental human infection. Emerg Infect Dis. 2008; 14:1553-1557. [PubMed: 18826818]

20. Rockx B, De Wit M, Vennema H, et al. Natural history of human calicivirus infection: a prospective cohort study. Clin Infect Dis. 2002; 35:246-253. [PubMed: 12115089]

21. Patel MM, Widdowson M-A, Glass RI, Akazawa K, Vinjé J, Parashar UD. Systematic literature review of role of noroviruses in sporadic gastroenteritis. Emerg Infect Dis. 2008; 14:1224-1231. [PubMed: 18680645]

22. Parrino TA, Schreiber DS, Trier JS, Kapikian AZ, Blacklow NR. Clinical immunity in acute gastroenteritis caused by Norwalk agent. N Engl J Med. 1977; 297:86-89. [PubMed: 405590]

23. Pang XL, Joensuu J, Vesikari T. Human calicivirus-associated sporadic gastroenteritis in Finnish children less than two years of age followed prospectively during a rotavirus vaccine trial. Pediatr Infect Dis J. 1999; 18:420-426. [PubMed: 10353514]

24. Monica B, Ramani S, Banerjee I, et al. Human caliciviruses in symptomatic and asymptomatic infections in children in Vellore, South India. J Med Virol. 2007; 79:544-551. [PubMed: 17385696]

25. Bon F, Fascia P, Dauvergne M, et al. Prevalence of group A rotavirus, human calicivirus, astrovirus, and adenovirus type 40 and 41 infections among children with acute gastroenteritis in Dijon, France. J Clin Microbiol. 1999; 37:3055-3058. [PubMed: 10449507]

26. de Wit MA, Koopmans MP, Kortbeek LM, et al. Sensor, a population-based cohort study on gastroenteritis in the Netherlands: incidence and etiology. Am J Epidemiol. 2001; 154:666-674. [PubMed: 11581101]

27. de Wit MA, Koopmans MP, Kortbeek LM, van Leeuwen NJ, Bartelds AI, van Duynhoven YT. Gastroenteritis in sentinel general practices, The Netherlands. Emerg Infect Dis. 2001; 7:82-91. [PubMed: 11266298]

28. O'Ryan ML, Mamani N, Gaggero A, et al. Human caliciviruses are a significant pathogen of acute sporadic diarrhea in children of Santiago, Chile. J Infect Dis. 2000; 182:1519-1522. [PubMed: 11023476]

29. Parashar UD, Li JF, Cama R, et al. Human caliciviruses as a cause of severe gastroenteritis in Peruvian children. J Infect Dis. 2004; 190:1088-1092. [PubMed: 15319858]

30. Oh DY, Gaedicke G, Schreier E. Viral agents of acute gastroenteritis in German children: prevalence and molecular diversity. J Med Virol. 2003; 71:82-93. [PubMed: 12858413]

31. Food Standards Agency. A report of the study of infectious intestinal disease in England. London: The Stationery Office; 2000.

32. Le Guyader FS, Mittelholzer C, Haugarreau L, et al. Detection of noroviruses in raspberries associated with a gastroenteritis outbreak. Int J Food Microbiol. 2004; 97:179-186. [PubMed: 15541804]

33. Lopman BA, Reacher MH, Vipond IB, Sarangi J, Brown DW. Clinical manifestation of norovirus gastroenteritis in health care settings. Clin Infect Dis. 2004; 39:318-324. [PubMed: 15306997]

34. Nilsson M, Hedlund KO, Thorhagen M, et al. Evolution of human calicivirus RNA in vivo: accumulation of mutations in the protruding P2 domain of the capsid leads to structural changes and possibly a new phenotype. J Virol. 2003; 77:13117-13124. [PubMed: 14645568]

35. Kaufman SS, Chatterjee NK, Fuschino ME, et al. Characteristics of human calicivirus enteritis in intestinal transplant recipients. J Pediatr Gastroenterol Nutr. 2005; 40:328-333. [PubMed: 15735487]

36. Mattner F, Sohr D, Heim A, Gastmeier P, Vennema H, Koopmans M. Risk groups for clinical complications of norovirus infections: an outbreak investigation. Clin Microbiol Infect. 2006; 12:69-74. [PubMed: 16460549]

37. Norovirus activity — United States, 2006-2007. MMWR Morb Mortal Wkly Rep. 2007; 56:842846. [PubMed: 17717513]

38. Harris JP, Edmunds WJ, Pebody R, Brown DW, Lopman BA. Deaths from norovirus among the elderly, England and Wales. Emerg Infect Dis. 2008; 14:1546-1552. [PubMed: 18826817] 
39. Turcios-Ruiz RM, Axelrod P, John KS, et al. Outbreak of necrotizing enterocolitis caused by norovirus in a neonatal intensive care unit. J Pediatr. 2008; 153:339-344. [PubMed: 18534621]

40. Chen SY, Tsai CN, Lai MW, et al. Norovirus infection as a cause of diarrhea-associated benign infantile seizures. Clin Infect Dis. 2009; 48:849-855. [PubMed: 19239351]

41. Khan RR, Lawson AD, Minnich LL, et al. Gastrointestinal norovirus infection associated with exacerbation of inflammatory bowel disease. J Pediatr Gastroenterol Nutr. 2009; 48:328-333. [PubMed: 19274789]

42. Levy AG, Widerlite L, Schwartz CJ, et al. Jejunal adenylate cyclase activity in human subjects during viral gastroenteritis. Gastroenterology. 1976; 70:321-325. [PubMed: 765182]

43. Agus SG, Dolin R, Wyatt RG, Tousimis AJ, Northrup RS. Acute infectious nonbacterial gastroenteritis: intestinal histopathology: histologic and enzymatic alterations during illness produced by the Norwalk agent in man. Ann Intern Med. 1973; 79:18-25. [PubMed: 4721173]

44. Meeroff JC, Schreiber DS, Trier JS, Blacklow NR. Abnormal gastric motor function in viral gastroenteritis. Ann Intern Med. 1980; 92:370-373. [PubMed: 6766695]

45. Huang P, Farkas T, Marionneau S, et al. Noroviruses bind to human ABO, Lewis, and secretor histo-blood group antigens: identification of 4 distinct strain-specific patterns. J Infect Dis. 2003; 188:19-31. [PubMed: 12825167]

46. Marionneau S, Ruvoen N, Le Moullac-Vaidye B, et al. Norwalk virus binds to histo-blood group antigens present on gastroduodenal epithelial cells of secretor individuals. Gastroenterology. 2002; 122:1967-1977. [PubMed: 12055602]

47. Tan M, Jiang X. Norovirus and its histo-blood group antigen receptors: an answer to a historical puzzle. Trends Microbiol. 2005; 13:285-293. [PubMed: 15936661]

48. Hutson AM, Airaud F, LePendu J, Estes MK, Atmar RL. Norwalk virus infection associates with secretor status genotyped from sera. J Med Virol. 2005; 77:116-120. [Erratum, J Med Virol 2005;77:455.]. [PubMed: 16032732]

49. Lindesmith L, Moe C, Marionneau S, et al. Human susceptibility and resistance to Norwalk virus infection. Nat Med. 2003; 9:548-553. [PubMed: 12692541]

50. Thorven M, Grahn A, Hedlund KO, et al. A homozygous nonsense mutation $(428 \mathrm{G} \rightarrow \mathrm{A})$ in the human secretor (FUT2) gene provides resistance to symptomatic norovirus (GGII) infections. J Virol. 2005; 79:15351-15355. [PubMed: 16306606]

51. Tan M, Jin M, Xie H, Duan Z, Jiang X, Fang Z. Outbreak studies of a GII-3 and a GII-4 norovirus revealed an association between HBGA phenotypes and viral infection. J Med Virol. 2008; 80:1296-1301. [PubMed: 18461617]

52. Yee EL, Palacio H, Atmar RL, et al. Widespread outbreak of norovirus gastroenteritis among evacuees of Hurricane Katrina residing in a large "megashelter" in Houston, Texas: lessons learned for prevention. Clin Infect Dis. 2007; 44:1032-1039. [PubMed: 17366445]

53. Widdowson MA, Cramer EH, Hadley L, et al. Outbreaks of acute gastroenteritis on cruise ships and on land: identification of a predominant circulating strain of norovirus - United States 2002. J Infect Dis. 2004; 190:27-36. [Erratum, J Infect Dis 2004;190:2198.]. [PubMed: 15195240]

54. Xerry J, Gallimore CI, Iturriza-Gomara M, Allen DJ, Gray JJ. Transmission events within outbreaks of gastroenteritis determined through analysis of nucleotide sequences of the P2 domain of genogroup II noroviruses. J Clin Microbiol. 2008; 46:947-953. [PubMed: 18216210]

55. Atmar RL, Neill FH, Romalde JL, et al. Detection of Norwalk virus and hepatitis A virus in shellfish tissues with the PCR. Appl Environ Microbiol. 1995; 61:3014-3018. [PubMed: 7487032]

56. Daniels NA, Bergmire-Sweat DA, Schwab KJ, et al. A foodborne outbreak of gastroenteritis associated with Norwalk-like viruses: first molecular traceback to deli sandwiches contaminated during preparation. J Infect Dis. 2000; 181:1467-1470. [PubMed: 10753727]

57. Baert L, Uyttendaele M, Stals A, et al. Reported foodborne outbreaks due to noroviruses in Belgium: the link between food and patient investigations in an international context. Epidemiol Infect. 2009; 137:316-325. [PubMed: 19134230]

58. Ozawa K, Oka T, Takeda N, Hansman GS. Norovirus infections in symptomatic and asymptomatic food handlers in Japan. J Clin Microbiol. 2007; 45:3996-4005. [PubMed: 17928420] 
59. Belliot G, Lavaux A, Souihel D, Agnello D, Pothier P. Use of murine norovirus as a surrogate to evaluate resistance of human norovirus to disinfectants. Appl Environ Microbiol. 2008; 74:33153318. [PubMed: 18378650]

60. Sandora TJ, Shih MC, Goldmann DA. Reducing absenteeism from gastrointestinal and respiratory illness in elementary school students: a randomized, controlled trial of an infection-control intervention. Pediatrics. 2008; 121(6):e1555-e1562. [PubMed: 18519460]

61. Periwal SB, Kourie KR, Ramachandaran N, et al. A modified cholera holotoxin CT-E29H enhances systemic and mucosal immune responses to recombinant Norwalk virus-virus like particle vaccine. Vaccine. 2003; 21:376-385. [PubMed: 12531635]

62. Guerrero RA, Ball JM, Krater SS, Pacheco SE, Clements JD, Estes MK. Recombinant Norwalk virus-like particles administered intranasally to mice induce systemic and mucosal (fecal and vaginal) immune responses. J Virol. 2001; 75:9713-9722. [PubMed: 11559804]

63. Ball JM, Graham DY, Opekun AR, Gilger MA, Guerrero RA, Estes MK. Recombinant Norwalk virus-like particles given orally to volunteers: phase I study. Gastroenterology. 1999; 117:40-48. [PubMed: 10381908]

64. Tacket CO, Sztein MB, Losonsky GA, Wasserman SS, Estes MK. Humoral, mucosal, and cellular immune responses to oral Norwalk virus-like particles in volunteers. Clin Immunol. 2003; 108:241-247. [PubMed: 14499247]

65. Chang KO, George DW. Interferons and ribavirin effectively inhibit Norwalk virus replication in replicon-bearing cells. J Virol. 2007; 81:12111-12118. [PubMed: 17855555] 


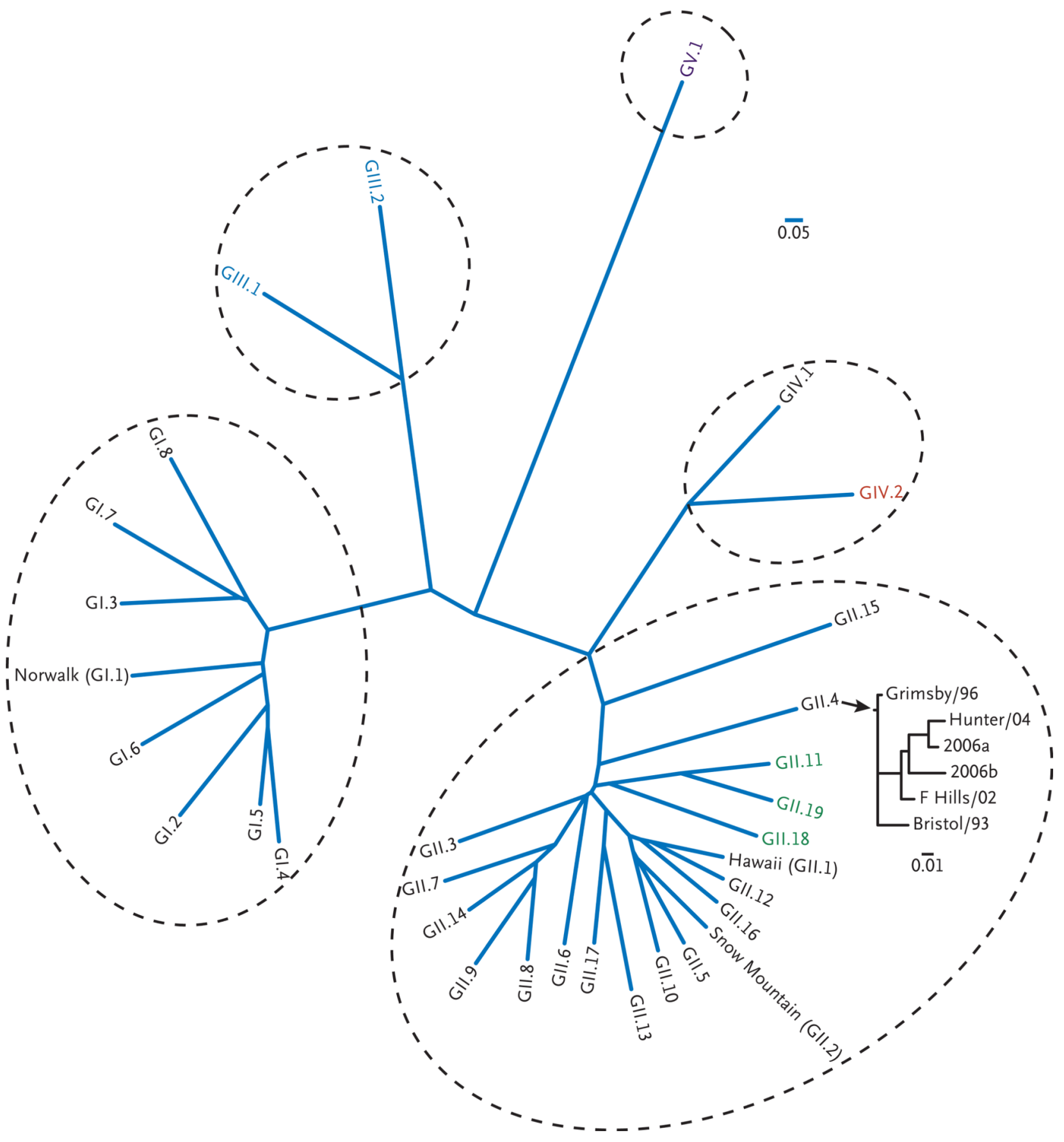

Figure 1. Phylogenetic Analysis of Noroviruses

Noroviruses are a separate genus in the family Caliciviridae and have great diversity of genogroups, genotypes, and subtypes. Genogroups III and V have been identified only in animals. Strain GI.1 was the original Norwalk virus; other classic viruses named for the locations of outbreaks they caused are shown; strain GII.4 has become the predominant strain in the United States and throughout the world. This multiple alignment of 52 calicivirus viral protein (VP) 1 capsid amino acid sequences was performed with the use of Clustalw2 (http://www.ebi.ac.uk/Tools/clustalw2/index.html), and the phylogenetic analyses were performed with programs in the Phylip package, version 3.6. The scale bars represent the unit for the expected number of substitutions per site. Similar analyses that were 
performed for recent GII.4 norovirus strains show the emergence of strains every 2 to 4 years. Human prototype viruses are listed in black, porcine viruses GII.11, GII.19, and GII. 18 are shown in green, bovine viruses are shown in blue, a murine virus is shown in purple, and a lion virus GIV.2 is shown in red. The prototype strains and the sequence accession references used for this analysis are listed in Table 1 in the Supplementary Appendix. 


\section{0 molecules ( 90 dimers) of VP1}

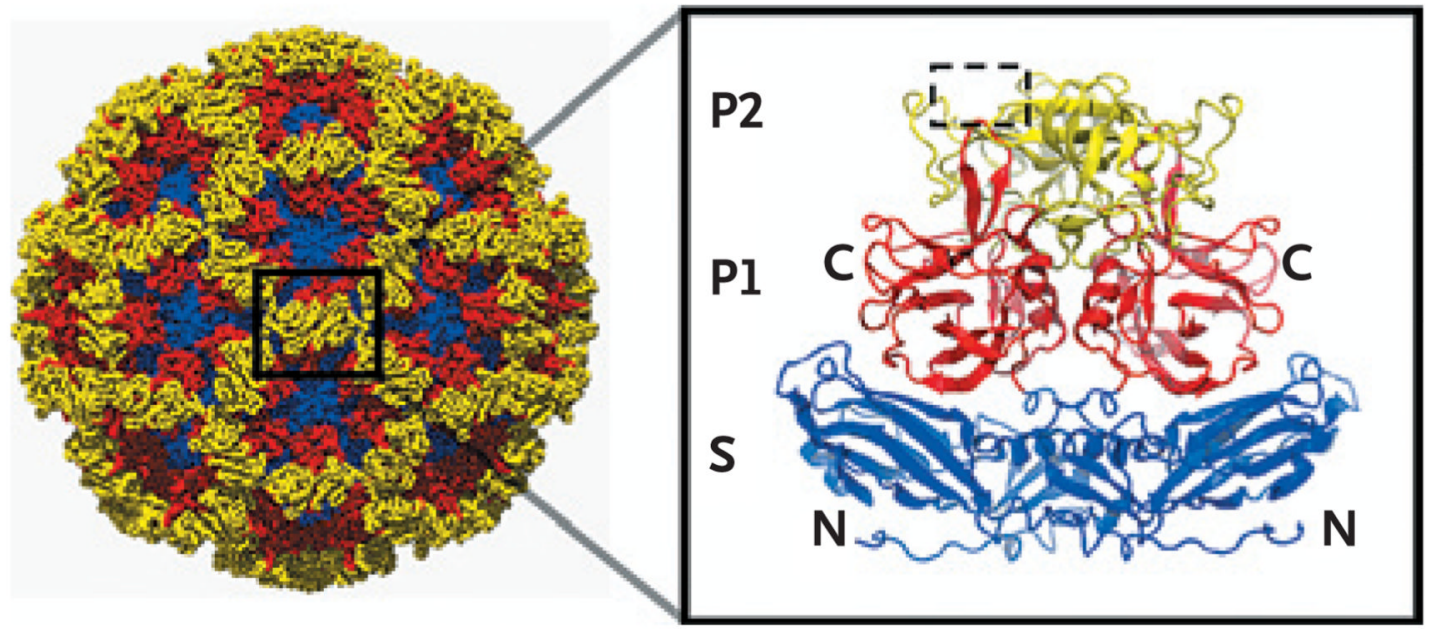

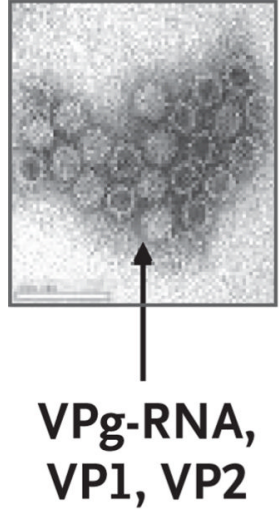

Subgenomic RNA ( 2.8 kb)
Genomic RNA ( 7.7 kb)

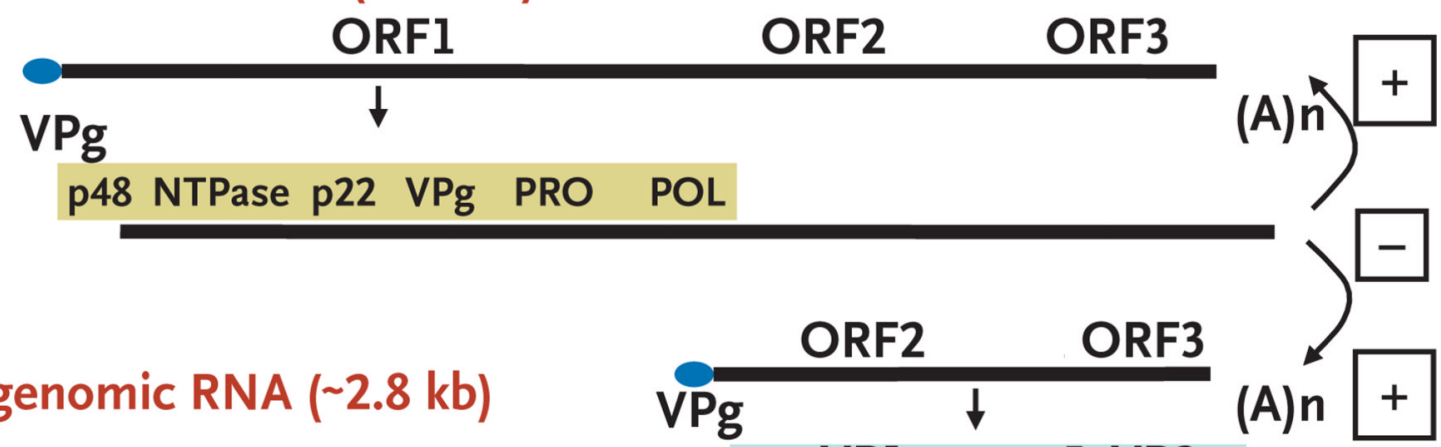

Figure 2. Structure of Norwalk Virus Capsid and Genome

The top left panel shows the icosahedral capsid structure (showing only the backbone atoms) of Norwalk virus formed by 180 molecules (90 dimers) of the capsid viral protein 1 (VP1), color-coded to show the three domains illustrated in the ribbon representation of the VP1 dimer extracted from the capsid structure (top right panel). The terminals of the capsid dimers are shown, and the region of binding to histo-blood antigen carbohydrate is shown in the dashed box. The bottom panel illustrates virus particles observed on transmission electron microscopy. Particles lacking the genome have dark interiors caused by penetration of the negative stain. The Norwalk virus genome is 7654 nucleotides of positive (+)-sense, single-stranded RNA. A viral protein called VPg is covalently attached to the $5^{\prime}$ end of the RNA, and a polyA tail is at the $3^{\prime}$ end. The incoming genomic RNA functions as a messenger RNA, and it codes for three open reading frames (ORFs). ORF1 is translated as a polyprotein that is cleaved by the virus-encoded protease (Pro) to produce six proteins: p48, nucleoside triphosphatase, p22, VPg, Pro (protease) and Pol (RNA-dependent RNA 
polymerase). These proteins function in the replication process to copy the (+)-sense genomic RNA into a (-)-sense copy that is used as a template to produce a (+)-sense subgenomic RNA. The subgenomic RNA is translated to produce the major capsid protein (VP1) and a few molecules of a second capsid protein (VP2) that can self-assemble into viruslike particles when these two proteins are expressed alone. ${ }^{5,6} \mathrm{P}$ denotes protruding domain, and S shell domain; (A)n indicates that the $3^{\prime}$ end of the RNA is polyadenylated. 


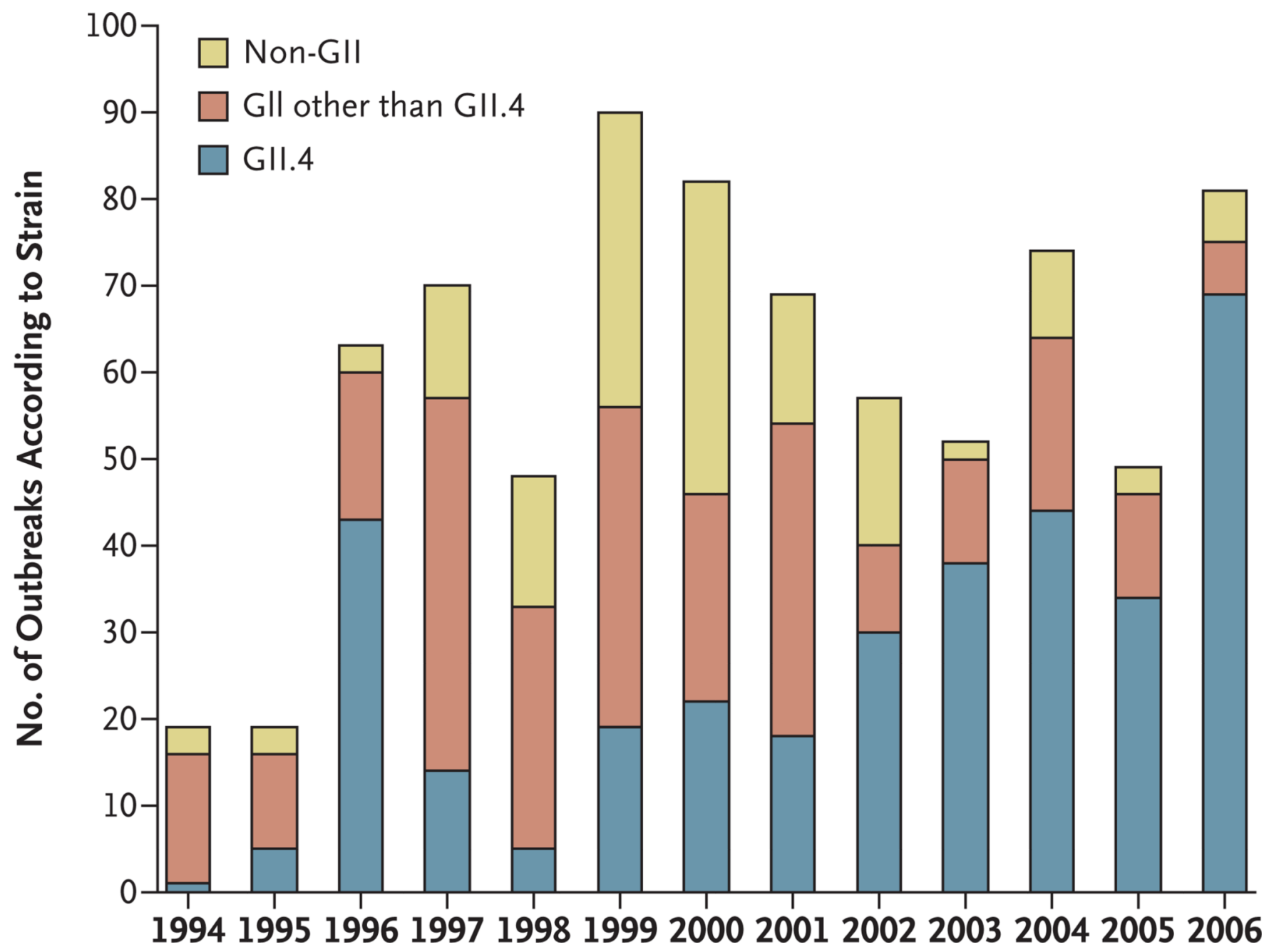

Figure 3. Outbreaks of Noroviruses in the United States, 1994 to 2006, According to Genotype and Genogroup

The original Norwalk virus strain, GI.1, is rarely present, whereas GII.4 has become the pandemic strain. The increase in outbreaks after 1996 reflects the application of new polymerase-chain-reaction diagnostics and not an absolute increase in the number of outbreaks that occurred. 


\section{Table 1}

Clinical and Epidemiologic Features of Norovirus Infections.

\begin{tabular}{|c|c|}
\hline Variable & Description \\
\hline Age predisposition & Affects all ages. \\
\hline Seasonality & Occurs year round; outbreaks tend to peak in cold weather. \\
\hline Settings & $\begin{array}{l}\text { Outbreaks often occur in semi-closed environments (e.g., nursing homes, hospitals, cruise ships), the military, and } \\
\text { schools and at recreational activities (e.g., sports events, camping trips, travel) that favor person-to-person spread. }\end{array}$ \\
\hline Incubation period & $10-51 \mathrm{hr}$. \\
\hline Symptoms & $\begin{array}{l}\text { Sudden onset of vomiting (more common in children) and diarrhea (more common in adults). Diarrheal stools } \\
\text { usually contain no blood, mucus, or leukocytes. Asymptomatic infections are estimated to occur in approximately } \\
\text { one third of infected persons. }\end{array}$ \\
\hline Severity of illness & $\begin{array}{l}\text { Overall, less severe than many other diarrheal infections but can lead to dehydration and hospitalization, especially } \\
\text { among children }<5 \mathrm{yr} \text { of age and adults }>65 \mathrm{yr} \text { of age. }\end{array}$ \\
\hline Duration of illness & $\begin{array}{l}\text { Typically } 28-60 \mathrm{hr} \text {; longer than } 3 \text { days in } 15 \% \text { of cases; longer illness in immunocompromised persons and adults } \\
\text { with underlying illnesses. }\end{array}$ \\
\hline Viral shedding & $\begin{array}{l}\text { Peaks 1-3 days after onset of illness. Recent data indicate that viral antigen may be shed for up to } 56 \text { days. } \\
\text { Shedding can be prolonged in immuno-compromised persons. Shedding may precede illness. }\end{array}$ \\
\hline $\begin{array}{l}\text { Mode of transmission } \\
\text { and vehicles }\end{array}$ & $\begin{array}{l}\text { Fecal-oral; aerosol-vomitus; contact with fomites; food, water, or environmental contamination; foods can be } \\
\text { contaminated at the source (e.g., oysters, raspberries) or during preparation by food handlers. }\end{array}$ \\
\hline Immunity & $\begin{array}{l}\text { Illness results in short-term homologous immunity; infections can occur with other strains or with the same strain } \\
\text { later in life; repeated exposure may generate long-term immunity. }\end{array}$ \\
\hline Treatment & $\begin{array}{l}\text { Supportive therapy to prevent dehydration; no specific antiviral therapy available. Vaccine development is in early } \\
\text { phase. }\end{array}$ \\
\hline Reservoir & Humans; recent evidence raises possibility of animal reservoir. \\
\hline
\end{tabular}




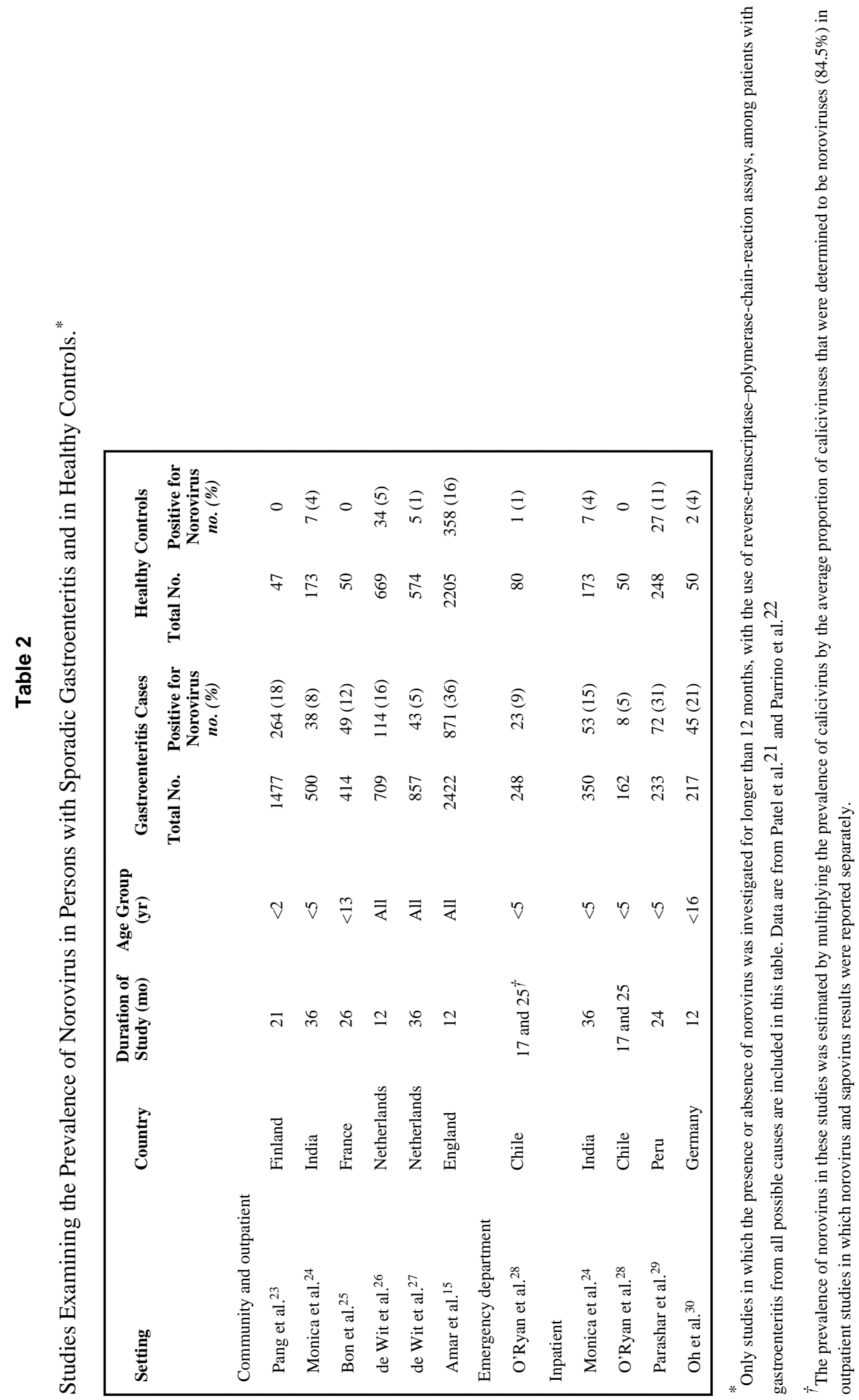

